\title{
Erratum
}

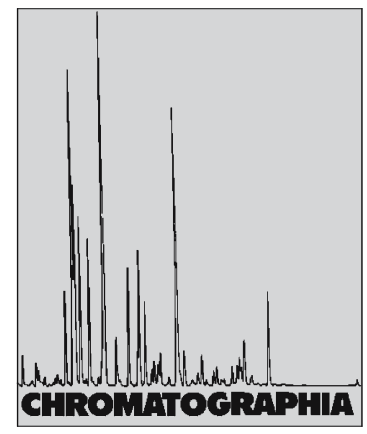

2008, 67, 343

\section{Synthesis of Molecular Imprinted Polymer Networks}

\author{
S. Rimmer ${ }^{\square}$ \\ The Polymer Centre, Lancaster University, Lancaster, Lancs., LA1 4YA, UK; E-Mail: s.rimmer@sheffield.ac.uk
}

\section{Erratum to: Chromatographia (1998) 47(7-8):470-474 DOI 10.1007/BF02466483}

Unfortunately, the original article has been published with a wrong volume number in the footer. The correct footer is:

Chromatographia Vol. 47, No. 7/8, April 1998, Review Paper 